\title{
Gobierno de oposición y modernización educativa. El conflicto político por la descentralización de la educación en Baja California, 1989-1993
}

Víctor Alejandro Espinoza Valle* EL COLEGIO DE LA FRONTERA NORTE

\begin{abstract}
Se examina el proceso de descentralización educativa en Baja California, última entidad del país en signar el ANMEB. La tardía formalización del Acuerdo se explica a partir del conflicto político entre el primer gobierno estatal de oposición -encabezado por Ernesto Ruffo Appel-y las secciones locales del SNTE.
\end{abstract}

MODERNIZACIÓN EDUCATIVA. IMPLICACIONES REGIONALES

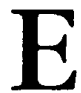
n el Programa para la Modernización de la Educación 1989. 1994 se postuló la educación básica como prioridad del nuevo modelo educativo; asimismo, se establecieron las bases del Acuerdo Nacional para la Modernización de la Educación Básica (ANMEB), firmado en mayo

* Agradezco el apoyo de Ofelia Silvia Nieto Méndez, becaria de investigación, en la revisión hemerográfica. de 1992 por los gobernadores de las entidades federativas, la dirigencia del Sindicato Nacional de Trabajadores de la Educación (SNTE) y el titular de la Secretaría de Educación Pública (SEP).

En el ANMEB se establecieron las políticas para la modernización de la educación básica, sus áreas y acciones principales y la participación de las instituciones y de los diferentes niveles de gobierno. De esta forma quedó definida la intervención de la federación, los gobiernos estatales y el SNTE en la instrumentación de las políticas y acciones para la modernización de la educación en cada estado. 
En el marco del ANMEB, la descentralización del sistema educativo destaca como uno de los principales objetivos de la reforma educativa, iniciándose el traspaso a los gobiernos estatales de la infraestructura física, la administración y los recursos financieros con que la SEP venía prestando los servicios educativos a nivel estatal. ${ }^{1}$

En el plano sindical, la modernización del sistema educativo produjo una reorganización del SNTE como organismo nacional de representación de los trabajadores de la educación; entre otras consecuencias, destaca el traspaso de las facultades de negociación y titularidad de las condiciones generales de trabajo a las secciones sindicales estatales.

El actual proceso de descentralización educativa ha transformado cualitativamente la estructura formal, las

${ }^{1}$ Sobre el tema de la descentralización, Aurora Loyo ha señalado: "El diagnóstico [gubernamental, contenido en el ANMEB] -aclaración del autor-, implícito puede ser correcto o incorrecto, pero sobre esa base se establece un conjunto de medidas que profundizan la. descentralización entendida como una reorganización administrativa que quita al centro la sobrecarga operativa y refuerza su capacidad decisional y de control. El Acuerdo sienta sólo bases generales y sus lineamientos abren nuevos ámbitos de conflicto en los que se definirán los grados y modalidades que adoptará en los hechos la reorganización. Sabemos ya que las diversidades regionales se manifiestan con fuerza y que en estos momentos en Nuevo León o Chiapas los maestros, directores e inspectores, funcionarios y burócratas, dirigentes delegacionales y seccionales, fuerzas políticas estatales y muy diversas organizaciones sociales y políticas externas al sistema educativo, buscan poder $o$ influencia bajo las nuevas condiciones a las que da lugar la federalización y los importantes recursos económicos y políticos que conlleva", Loyo, “'Modernización?”, 1993, p. 343. posiciones y las relaciones de los principales actores del proceso educativo, incidiendo con ello en las estructuras locales de podery propiciando la apertura de nuevos espacios y la emergencia de nuevos actores sociales. ${ }^{2}$

Por lo anterior, es de particular importancia conocer las implicaciones de la descentralización a nivel regional y local, y reflexionar en torno a las posiciones de los actores sociales - tanto en el ámbito escolar como en el de las instituciones gubernamentales--.

En Baja California, este proceso de descentralización educativa ha tenido como marco el cambio político que alienta la sociedad civil hacia finales de los años ochenta. De esta manera, al gobierno panista le ha tocado mate. rializar el proyecto federal, abanderando el proceso de modernización polí. tica y de manera destacada la reforma del estado.

\section{CAMBIO DE GOBIERNO Y TRANSICIÓN CORPORATIVA}

En 1988, 1989 y 1992 la sociedad civil bajacaliforniana, mediante el sufragio, expresaba su veredicto sobre los gobiernos estatales anteriores y su desacuerdo con el sistema político, percibido como centralista y vertical. Baja California fue el único de los seis estados norteños donde en 1988 triunfó el candidato presidencial del Frente Democrático Nacional, ingeniero Cuauhtémoc Cárdenas. Un año después, en el verano de 1989, el candidato panista

${ }^{2}$ Véase Calvo, Acuerdo, 1993, p. 5. 


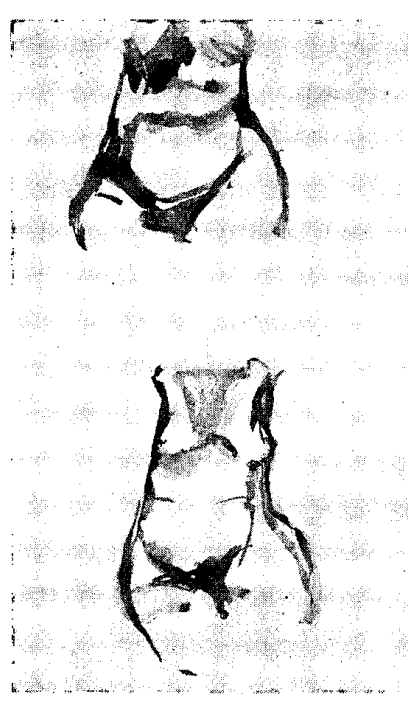

a la gubernatura de la entidad, Ernesto Ruffo Appel, obtenía 52.6\% de los votos para convertirse en el primer gobernador de oposición en la historia política mexicana. Además, el Partido Ac. ción Nacional (PAN) obtuvo dos de las cuatro presidencias municipales en disputa - Tijuana y Ensenada-y nueve de las quince diputaciones de mayoría. Esta victoria panista se repetiría en las elecciones siguientes -2 de agosto de 1992-, sumando tres alcaldias: Tijuana, Ensenada y Tecate, y ocho de las quince diputaciones de mayoría. ${ }^{3}$

${ }^{3}$ A raíz de las elecciones del 2 de julio de 1989, el congreso local quedó integrado por nueve diputados del pan y seis del Partido Revolucionario Institucional (PRI). Además, obtuvieron un diputado de representación proporcio-

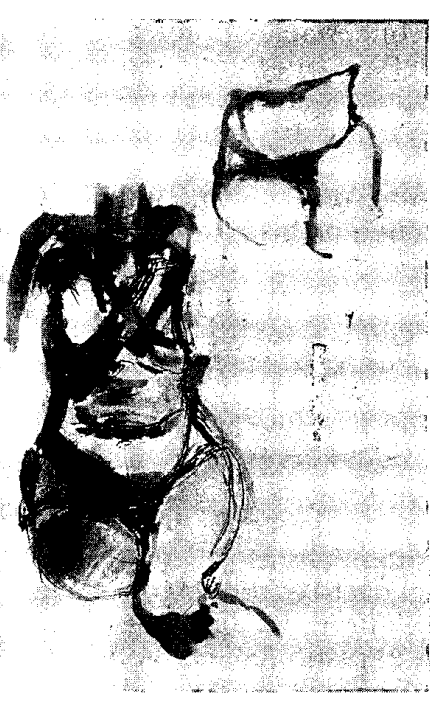

Sin duda, las elecciones más competidas y de mayor trascendencia fueron las del verano de 1989. El triunfo de Ruffo Appel era el reconocimiento político más importante del gobierno de Carlos Salinas de Gortari y con él, del regimen posrevolucionario. Intentaba ser el anuncio de una nueva

nal los partidos: Auténtico de la Revolución Mexicana (PARM), Popular Socialista (PPS), Frente Cardenista de Reconstrucción Nacional (PFCRN) y de la Revolución Democrática (PRD). En el verano de 1992 el PRI sumaba la pérdida de la alcaldía de Tecate, para conservar únicamente la de la capital del estado-Mexicali-y siete de las quince diputaciones de mayoría. El PAN obtuvo, además de las tres alcaldias mencionadas, ocho diputaciones distritales y el PRD, las cuatro curules de representación proporcional. Puede consultarse al respecto: Espinoza, Reforma, 1993. 
forma de concertación política: la evidencia del proyecto de modernización política del gobierno federal. A cinco años del histórico reconocimiento del triunfo panista, los saldos trascendentes en el terreno político y social se refieren a los cambios experimentados en la estructura corporativa. Ruffo Appel asumió la gubernatura sin los compromisos con las organizaciones locales de todo gobierno priísta. Al contrario, el triunfo panista se logró enfrentando la tradición corporativa $y$, en gran medida, con el apoyo de una ciudadanía como la bajacaliforniana, que ha crecido al margen de las prácticas patrimonialistas y clientelares propias del pacto corporativo. Esto le permitió, a diferencia de lo que ha sucedido en el plano federal, gobernar enfrentando y transformando la relación con las dirigencias de las organizaciones tradicionales. Éste ha sido el cambio más conspicuo: el desplazamiento de los líderes de viejo cuño. Al negociar directamente con la ciudadanía la problemática social, los líderes pierden el monopolio de la gestión de las demandas de sus agremiados. Esto necesariamente provoca el desgaste de las organizaciones y el cuestionamiento de los liderazgos tradicionales, ya que se ha truncado el intercambio de bienes - políticos, legislativos, laborales y económicos- entre el gobierno y los líderes. De ello encontramos sobrados ejemplos: desde las organizaciones de transportistas, pasando por los burócratas y extendiéndose al movimiento urbano popular. ${ }^{4}$

${ }^{4}$ Sobre el tema puede verse: Espinoza, y Hernández, "Tendencias", 1993, pp. 25-29.
En el caso de la relación del gobierno del estado con las organizaciones federales, como el SNTE, fue hasta la mitad del periodo gubernativo de Ernesto Ruffo cuando se iniciaron las fricciones entre la administración estatal y la dirigencia magisterial.

En Baja California, como en otros estados de la república, el magisterio es el colectivo más numeroso de los trabajadores del sector público. Por ejemplo, en 1990, en el sector público de Baja California trabajaban un total de $\mathbf{5 6} 578$ personas, de las cuales 25020 , es decir $44.2 \%$, era personal de la educación. Para septiembre de 1992 el total ascendía a 28569 , cifra que se elevaría tres meses después, según otra base de datos, a 29177 trabajadores. De éstos, 16815 afiliados a la sección federal 2, y 12362 a la 37 estatal, del SNTE. ${ }^{5}$

Como ha sucedido con otros núcleos de la población, por ejemplo los transportistas, Ruffo Appel decidió apoyar a grupos disidentes dentro del magisterio estatal. Éste fue el caso de Ricardo Romo Castro, dirigente de la delegación D-II-16 y del llamado Movimiento Democrático de la Base. En el contexto de la fuerte pugna en torno a la federalización-que analizamos en el siguiente apartado- se presentaba la oportunidad para contar con alia-

\footnotetext{
${ }^{5}$ Los datos de 1990 fueron tomados de: Espinoza, Reforma, 1993, pp. 94, 99 y 113; los de septiembre de 1992 fueron proporcionados por la Dirección de Estadistica de la Secretaría de Educación y Bienestar Social del Gobierno del estado de Baja California, y los de noviem. bre de 1992 fueron tomados del trabajo de Sandoval, "Maestras", 1993, p. 81.
} 
dos dentro de la sección 37 del SNTE. Al parecer, el gobierno del estado se comprometía a otorgar una serie de prestaciones, como: préstamos para la construcción de 236 viviendas, pagos atrasados por concepto de prima vacacional y préstamos con interés preferencial. Hacia finales de 1992, el grupo encabezado por Romo Castro inició movilizaciones que tenían por objeto lograr la renovación del Comité Ejecutivo Seccional mediante el voto directo y universal del magisterio y no como señalan los estatutos renovados de la organización, a través del voto secreto de los delegados a un congreso. El candidato para la Secretaría General era el mismo Romo Castro y el candidato oficial, Roberto Pérez de Alba, quien resultaría electo mediante planilla única, durante el xx Congreso Extraordinario celebrado los días 5 y 6 de noviembre. Romo Castro se sintió traicionado y abandonado por el gobernador e inició unas movilizaciones contra él, las que culminaron con actos violentos durante julio de 1993. El 16 de julio, Romo y sus seguidores irrumpieron en el Palacio de Gobierno para exigir "el cumplimiento de las promesas de Ruffo". Después, el 26 de julio llegaron a la Casa de Gobierno por los mismos motivos y al día siguiente, en ocasión de la gira de trabajo del secretario de salud, Jesús Kumate Rodríguez, interceptaron violentamente al gobernador en el Hospital General de Mexicali, hechos en los que incluso miembros de su escolta fueron lesionados. Ése fue el final de la apuesta del ejecutivo por encontrar interlocutores en la negociación con el SNTE.

\section{EL CONFLICTO EN TORNO A LA} FEDERALIZACIÓN

Después de la firma del ANMEB, en mayo de 1992, se profundizó el proceso de descentralización de la educación que, como vimos, incluyó el traspaso de los bienes y activos, así como la absorción del personal de la educación federal por los estados. ${ }^{6}$ En Baja California, después de un fuerte conflicto entre el SNTE y el gobierno del estado, finalmente fue pactada la federalización. Fue la última de las entidades federativas en firmar el acuerdo respectivo. De nuevo, como había venido sucediendo desde 1989 , los factores que determinaron el proceso de descentralización son políticos. Las diferentes filiaciones partidistas de los actores activaron apoyos y extendieron el conflicto más allá de los marcos del contexto educativo.

Sin duda, el tema de controversia sería la absorción del personal federal por el ámbito estatal y su reglamentación. La propuesta de la administración de Ruffo Appel consistió en modificar y adicionar la Ley del Servicio Civil, que reglamenta las relaciones laborales entre el gobierno estatal y sus trabajadores. Propuesta a la que la dirigencia de las secciones 2 y 37 del SNTE

${ }^{6} \mathrm{El}$ proceso de descentralización educativa empezó a finales de los años setenta. Como señala Aurora Loyo: "(la desconcentración y descentralización del sistema educativo) se radicaliza y toma la forma de federalización en el ANMEB. Este proceso que se inicia en diciembre de 1977 cuando Fernando Solana se hace cargo de la SEP y fue revitalizado durante la gestión de Jesús Reyes Heroles, parece llegar a su meta con la firma de (dicho) documento". Loyo, “Modernización?", 1993, p. 341. 
se opusieron, argumentando, entre otras cosas, que el gobernador se proponía "pulverizar o desintegrar al SNTE". Entre septiembre y diciembre de 1992 se sucedieron movilizaciones, plantones, paros de labores y declaraciones sindicales. Más que discutir y negociar sobre la propuesta, la posición de los dirigentes era de total rechazo; el gobernador debía abandonar cualquier intento de reglamentación laboral a través de la Ley del Servicio Civil. ${ }^{7}$ La propuesta de Ruffo Appel no trataba de negar la existencia del SNTE, pues aun cuando la Ley del Servicio Civil reconoce en su artículo 61 la existencia de un solo sindicato o sindicato único, en un capítulo especial -artículos 153 al 165 y precisamente en este último-, se garantizaba la existencia del sindicato magisterial y su pertenencia a la agrupación nacional. Las secciones sindicales dejaron de lado su enfrentamiento que, como señala Aurora Loyo, "es previsible que se reforzarán las redes de poder del sindicalismo magisterial a nivel estatal: los dirigentes de diversos grupos magisteriales contarán con mayores recursos para negociar compromisos y alianzas políticas locales". 8 No se pensaba en el futuro; la ofensiva se

${ }^{7}$ Asi lo sostenía claramente Antonio Salvatierra González, en ese momento secretario general de la sección 37: "No se trata de discutir bondades o defectos de la iniciativa, sino de que se suprima totalmente y se deje la Ley del Servicio Civil como está. Ésa ha sido la posición de los maestros de base y no va a variar", Dávila, "Rechazo", 1992, p. 4. Sobre la propuesta de Ruffo Appel puede consultarse el desplegado, "Orientaciones", 1992, pp. 39-41A.

${ }^{8}$ Loyo, "Actores", 1992, p. 21. En la misma dirección apuntan las observaciones de Susan lanzó obedeciendo a motivaciones políticas y en una coyuntura de gran efervescencia: la calificación de las eleccciones del 2 de agosto de 1992.

El proceso electoral del verano -que contó con la presencia de observadores no gubernamentales-fue impugnado por el PRI, acusando a la administración de Ruffo Appel de haber permitido un gran fraude electoral. A las movilizaciones convocadas por el SNTE el 22 de septiembre y el 1 de octubre se sumaron otros contingentes, pero de manera destacada el Sindicato Único de Trabajadores al Servicio de los Poderes del Estado y Municipios e Instituciones Descentralizadas de Baja California (SUTSPEMIDBC), organización corporativa que encabezó la oposición a la política modernizadora del gobierno de Ruffo Appel. También se sumaron a la "cruzada pedagógica" organizaciones políticas como el PRI, el PPS y el PARM. El momento culminante de la presión ocurrió el 1 de octubre, en ocasión del III Informe del gobernador, cuando en el trayecto hacia el Palacio Legislativo fue interceptado por los manifestantes.

Las presiones dieron frutos; el 4 de octubre el gobernador aceptó dar marcha atrás en su propuesta de reforma y adición de La Ley del Servicio Civil. En realidad, el ejecutivo pretendía sortear la tensión y después intentar llevar a cabo las modificaciones; esta

Street: "Con la política de 'federalización' (descentralización) de la SEP, la suerte de los maestros y de sus conquistas históricas se somete a las leyes estatales, lo que en los hechos se traduce en una sobredeterminación de las prácticas políticas locales para las relacciones laborales", Street, "SNTE", 1993, p. 54. 


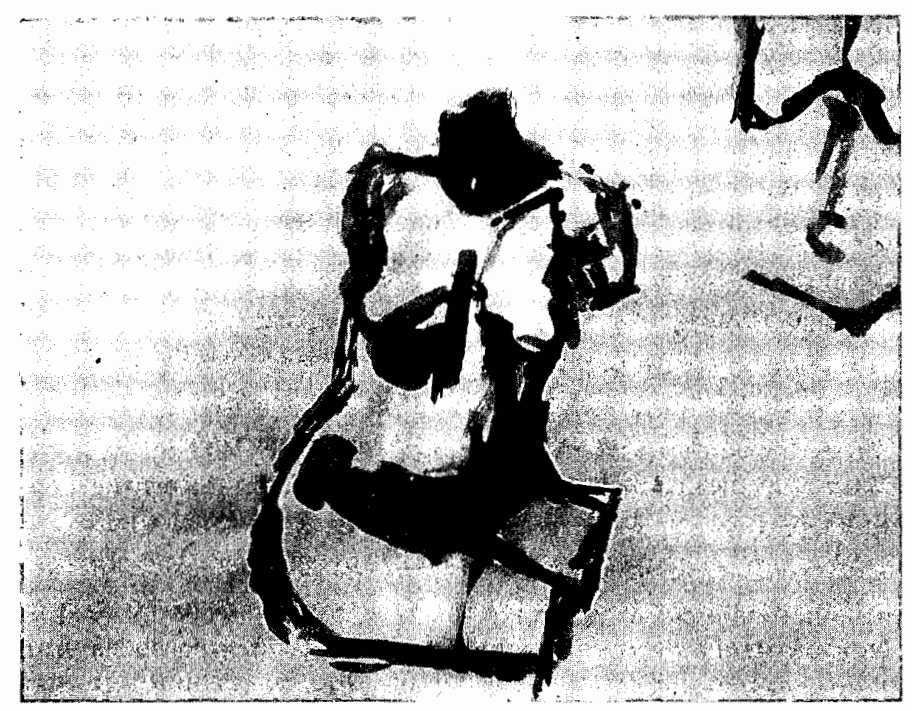

especie de tregua fue acordada directamente con la secretaria general del SNTE, Elba Esther Gordillo. En un comunicado hecho público el 6 de octubre, Ruffo Appel expresaba:

Una respuesta favorable de la SEP hará innecesarias las adecuaciones a la Ley del Servicio Civil. Sin embargo, de llevarse a cabo sostendremos como lo expresamos ayer aquí a la Profra. Elba Esther Gordillo, que dichas adecuaciones se realizarán con el consenso de los trabajadores. ${ }^{9}$

Dos meses más tarde y como fruto de las intensas presiones, el gobernador elaboró una nueva propuesta, misma que sería aprobada por el congreso

9 “Comunicado", 1992, p. 10. local siguiendo la vía rápida -"dispensa de trámite"- el 10 de diciembre, un día después de recibida. Se aceptaba por primera vez la homologación del personal federal con el estatal y la creación de un organismo descentralizado, "que regirá las relaciones entre el magisterio y el ejecutivo estatal en el marco de la modernización educativa". ${ }^{10}$ Además, quedaban satisfechas las demandas de la organización sindical, al dejarse de lado la propuesta de reforma del gobernador y adicionarse sólo dos artículos y un párrafo a otro más, a la Ley del Servicio Civil. ${ }^{11}$ De esta forma, el 14 de diciembre se po-

10 Véase Tejeda, "Entregó", 1992, p. 39.

1 Se adicionó al Artículo 151 el siguiente ordenamiento: "En el caso de las instituciones 
nía en marcha el Instituto de Servicios Educativos y Pedagógicos de Baja California (ISEP); en el acto inaugural el secretario de educación, Ernesto Zedillo Ponce de León, anunciaba que después de siete meses se consumaba la federalización educativa en el país.

\section{EL CONFLICTO ACTUAL ${ }^{12}$}

Con la creación del ISEP, la federación entregaba al estado 990 planteles, 11792 plazas docentes y administrativas y $19 \%$ de incremento de los recursos respecto del monto base contemplado para 1992. Respecto al proceso de homologación del personal, se anunciaba que se había llegado a un acuerdo en relación con el incremento para el personal de apoyo y asistencia a la educación, $15 \%$, y prima de vacaciones y aguinaldo de $20 \%$ para trabajadores en activo, es decir, no jubilados. ${ }^{13}$

descentralizadas la atención de seguridad social, será aquella que se consigne en sus ordenamientos de creación". Los otros dos artículos fueron agrupados en el capítulo único del título décimo primero, "De los trabajadores de la educación", estableciendo: "Artículo 153.- Los trabajadores al Servicio de la Educación, se agruparán en su propio Sindicato; Artículo 154.Los trabajadores al Servicio de la Educación disfrutarán de dos periodos anuales de vacacio. nes de diez días hábiles cada uno, conforme al calendario escolar; además de su salario ordinario gozarán de una prima vacacional no menor de $55 \%$ sobre los salarios que le correspondan durante dichos periodos", "Decreto", 1992, t. XCIX.

${ }^{12}$ Se refiere a fines de 1993 , cuando fue escrito este artículo. [N. del E.]

13 Véase, Arvizu, y Lizárraga, "Queda", 1992, pp. 1, 3 y 9; y Medrano, "Transferencia", 1992, pp. 1 y 4 .
En el futuro de la relación gobiernomagisterio se avisora un asunto generador de tensiones. Al igual que ha sucedido con otros rubros en el presente sexenio, va más allá del contexto educativo y agrega el conflicto con la federación. El gobierno de Ruffo exige a ésta el aumento en las participaciones como una medida fundamental para abatir el fuerte déficit público que arrastra la administración panista. Esta deuda pública es causada, según el gobierno estatal, por el gasto educativo, pues "los salarios de los maestros han crecido en mayor medida que los ingresos." De 1989 a la fecha, el renglón educativo creció $218 \%$, mientras que los ingresos aumentaron sólo $124 \%$. El gobierno del estado afirma que Baja California es "la entidad del país, que en términos porcentuales, invierte más en materia educativa en relación a su presupuesto". Para 1993 “47\% del presupuesto" se dedicó al ramo educativo. ${ }^{14}$ Esta posición augura una fuerte disputa local en torno a la homologación del personal y a la revisión de las condiciones de trabajo, clisputa que se convertirá en motivo para impugnar las participaciones federales a las entidades, fuente de fricción del gobierno de Ruffo Appel con la Secretaría de Hacienda y Crédito Público.

La falta de recursos económicos y su traducción en conflicto político, parece ser un serio obstáculo para la descentralización educativa en Baja California. Su resolución, como ha demostrado la historia reciente, depen-

14́ Dávila, "ERA", 1993, pp. 1 y 2A; Gómez y Olvera, "BC", 1993, pp. 1 y 2 A. 
de del trayecto político que siga la entidad; así, la modernización educativa parece encontrarse condicionada por los derroteros de la confrontación política local.

\section{BIBLIOGRAFÍ}

-Arvizu Gálvez, Carla y Francisco Lizárraga, "Queda en buenas manos la educación en BC: Zedillo", Diario 29, 15 de diciembre de 1992, Tijuana.

-Calvo Pontón, Beatriz, El Acuerdo nacional para la modernización de la educación básica: una interpretación regional desde la frontera norte, Unidad de Estudios Regionales, Universidad Autónoma de Ciudad Juárez, Ciudad Juárez, 1993 (Cuadernos de Trabajo 11).

"Comunicado al magisterio", El Mexicano, 6 de octubre de 1992, Tijuana.

-Dávila, Ismael, "Rechazo a nueva ley del Servicio Civil. Es firme la posición del magisterio", ElMexicano, 1 de octubre de 1992, Tijuana. , "ERA persiste en su pleito", $E l$ Mexicano, 23 de julio de 1993, Tijuana.

“Decreto no. 12", Periódico Oficial, Gobierno del Estado de Baja California, 11 de diciembre de 1992, Mexicali.

-Espinoza Valle, Víctor Alejandro, Reforma del Estado y empleo público. El conflicto laboral en el sector público de Baja California, Instituto Nacional de Administración Pública, México, 1993. , y Tania Hernández Vicencio,

"Tendencias de cambio en la estructura corporativa mexicana: Baja California, 1989-1992", El Cotidiano, División de Ciencias Sociales y Humanidades-UAM Azcapotzalco, año 8, núm. 52, enero-febrero de 1993, México.

-Gómez, Enrique, y Felipe Olvera, "BC tendrá adeudo de 460 munp", El Mexicano, 3 de agosto de 1993, Tijuana.

-Loyo Brambila, Aurora, " $i$ Modernización educativa o modernización del aparato educativo?", Revista Mexicana de Sociología, Instituto de Investigaciones Sociales-UNAM, año LV, núm. 2, abril-junio de 1993, México. "Actores y tiempos políticos en la modernización educativa", $E l$ Cotidiano, División de Ciencias Sociales y Humanidades-UAM Azcapotzalco, año 8, núm. 51, noviembre-diciembre de 1992, México.

-Medrano, José Luis, "Transferencia de 990 p"lanteles al Estado"; El Mexicano, 15 de diciembre de 1992, Tijuana.

-"Orientaciones a los maestros, padres de familia y opinión pública", Zeta, semana del 2 al 8 de octubre de 1992, Tijuana.

-Sandoval Flores, Etelvina, "Maestras y modernización educativa", El Cotidiano, División de Ciencias Sociales y Humanidades-uam Azcapotzalco, año 9, núm. 53, marzo-abril de 1993, México.

-Street, Susan, "SNTE iproyecto de quién?", El Cotidiano, División de Ciencias Sociales y Humanidades-UAM Azcapotzalco, año 9, núm.56, julio de 1993, México.

-rejeda, Laura, "Entregó Ruffo iniciativa para regir la relación con el magisterio en B.C.", El Financiero, 10 de diciembre de 1992, México. 


\section{SECUENCIA}

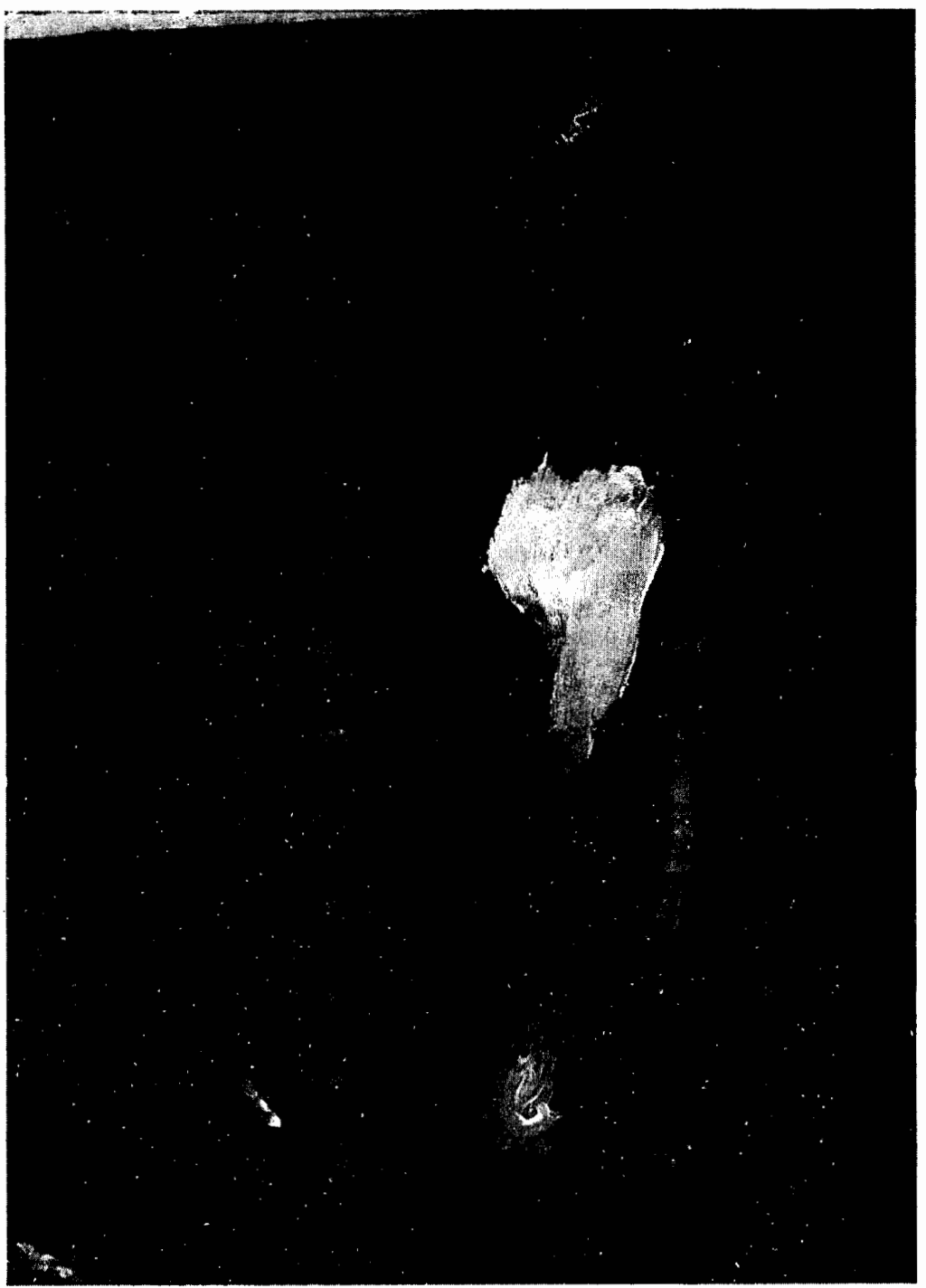

